\title{
$R X R \beta$ gene polymorphisms and the genetic predisposition to type 2 diabetes mellitus in South China
}

\author{
Haibing Yu*, Wei Hu*, Haiyan Pan, Shu Wang, Yan Yan, Huihuang Yang, Yuanlin Ding\#, Danli Kong ${ }^{\#}$ \\ Department of Epidemiology and Medical Statistics, School of Public Health, Guangdong Medical University, \\ Dongguan, 523808 Guangdong, China \\ *These authors contributed equally to this work. \\ "Corresponding Author: Danli Kong, Songshan Lake Technology Park, Dongguan, 523808, Guangdong, China, E-mail: \\ kdlgdmu@gdmu.edu.cn, Tel: 18211240058; Yuanlin Ding, Songshan Lake Technology Park, Dongguan, 523808, \\ Guangdong, China, E-mail: gdmcsbd@gdmc.edu.cn, Tel: 0769-22896366.
}

Received June 28, 2019; Accepted December 17, 2019

\begin{abstract}
Aims: To figure out the correlation between $R X R \beta$ gene polymorphisms and genetic predisposition to Type 2 Diabetes Mellitus (T2DM) in Chinese Han people from South China.

Methods and Material: In our case-control study, 1092 Chinese T2DM patients were included at the 10 hospitals from Shenzhen, Dongguan, Maoming, Zhanjiang, and Shaoguan of Guangdong Province, from November 2011 to October 2013. Moreover, 1092 healthful controls were also subsumed after body checks in the above hospitals. Extraction of genomic DNA from peripheral blood. Subsequently, single-nucleotide polymorphisms (SNPs) rs2744537 and rs2076310 were genotyped by the SNPscan ${ }^{\mathrm{TM}}$ kit.

Results: We not observed statistical differences at allele and genotype distributional frequencies of SNPs rs2744537 and rs2076310 between the two groups. Moreover, no statistical differences were also observed at the distributional frequencies of all genetic models between the two groups. In linkage disequilibrium analysis, the rs2076310 and rs2744537 of $R X R \beta$ gene have linkage disequilibrium. However, there were no statistical differences in the distributional frequencies of all Haplotypes by the haplotype analysis.

Conclusions: The genetic predisposition to T2DM may be not associated with SNPs rs2744537 and rs2076310 of $R X R \beta$ gene in the Chinese Han population from South China.
\end{abstract}

Key Words: Type 2 Diabetes Mellitus; Single nucleotide polymorphisms; RXR $\beta$ gene; Chinese Han population

\section{INTRODUCTION}

In the 8th Edition of the IDF Diabetes Atlas, current some 425 million people worldwide, or $8.8 \%$ of adults $20-79$ years, are estimated to have diabetes. Furthermore, this Atlas exhibited that the prevalence of diabetes in the Chinese people aged 20-79 years was $10.9 \%$. If these trends continue, by 2045 , the prevalence of diabetes will expand to $11.6 \%$ in China. ${ }^{1}$ diabetes is severely endocrine and metabolic diseases because of insulin deficiency or impaired insulin utilization. ${ }^{2}$ Type 2 Diabetes Mellitus (T2DM) was the most frequent type of diabetes, accounting for around $90 \%$ of all cases., ${ }^{3,4}$ T2DM was common among the elderly, but it is becoming more common among children, adolescents and young people across all world regions due to rising levels of obesity. ${ }^{5}$

The retinoid $\mathrm{X}$ receptor (RXR) is a type of nuclear receptor, consisting of three family members (RXR- $\alpha,-\beta$, and $-\gamma$ ). ${ }^{6}$ RXRs form both homodimers and heterodimers with various other nuclear receptors, including retinoic acid receptors (RARs), peroxisome proliferator-activated receptors (PPARs), liver $\mathrm{X}$ receptors (LXRs) and farnesoid X receptor (FXR) to regulate gene expression. ${ }^{7}$ Recently study found that RAR/RXR activation induces expression of hepatic glucokinase, which plays a key role in maintaining glucose homeostasis. ${ }^{8}$ thiazolidinedione (TZD) analogs, including pioglitazone, are used to reduce insulin resistance by activating the nuclear receptor PPAR $\gamma$, which is a

This is an open access journal, and articles are distributed under the terms of the Creative Commons Attribution-NonCommercial-ShareAlike 4.0 License, which allows others to remix, tweak, and build upon the work non-commercially, as long as appropriate credit is given and the new creations are licensed under the identical terms.

For reprints contact: weda-h@weda-h.org

How to cite this article: Yu HB, Hu W, Pan HY, Wang S, Yan Y, Yang HH, Ding YL, Kong DL. RXR $\beta$ gene polymorphisms and the genetic predisposition to type 2 diabetes mellitus in South China. J ADV HEALTH 2019; 1(4): 265-270. 
ligand-dependent transcription factor that functions in the form of heterodimers with RXRs. ${ }^{9} 10$ RXR/PPAR $\gamma$ activation exhibit glucose-lowering effects by combine full agonists of RXR, such as the 9-cis-Retinoic acid (9-cisRA), ${ }^{11}$ which negatively regulates glucose-stimulated insulin secretion and increase both adipogenesis and glucose uptake. ${ }^{12,13}$ Recent studies reported that Tributyltin chloride (TBT) may induce the promotion of triacylglycerol storage in adipocytes via RXR-dependent pathways. ${ }^{14}$ In addition, undifferentiated mesenchymal stem cells are transformed into adipocyte lines by activating RXR. ${ }^{15}$ RXR full agonists also exhibit TG elevation or hyperlipidemia effects via activation of RXR/LXR, which activation induces angiopoietin-like protein 3 (Angptl3). mice deficient in Angptl3 showed accumulation of triglyceride in the liver. ${ }^{16}$ Interestingly RXR antagonists LG100754 and LG101506, which function as RXR/PPAR agonists, were effective in the reduction of blood glucose level in $\mathrm{db} / \mathrm{db}$ mice. ${ }^{17,18}$ Natural RXR antagonist danthron, isolated from the traditional Chinese medicine rhubarb, improved insulin sensitivity in diet-induced obese mice. ${ }^{19}$ Some studies provide evidence that HX531, which is an RXR antagonist, improves leptin resistance in KKAy mice, ${ }^{20}$ as well as bring into play anti-obesity and anti-diabetes effects. $^{21,22}$ Moreover, The existing eye drug latanoprost is a selective $R X R \alpha$ antagonist and was demonstrated that improve glucose and lipid disorders in diabetic mice. ${ }^{23}$

On the whole, these findings implied that RXR gene might play a critical role in T2DM. Nonetheless, the exact mechanism by which RXR affects T2DM has not yet been elucidated. The genetic polymorphism of RXRs has been explored in the genetic susceptibility of T2DM. One study finds that GTGT in $R X R \alpha$ (rs1045570, rs3132291, rs4240711, and rs4842194) was more frequent in T2DM patients (6.9\%) than in controls $(4.4 \%)$ by haplotype analyses. ${ }^{24}$ Another study suggests that $\mathrm{G}$ allele in $R X R \gamma$ rs10918169 attained Statistical significance for an effect on T2DM risk $(\mathrm{OR}=1.31$, CI range from 1.23 to 1.40$) .{ }^{25}$ However, The association between $R X R \beta$, as one of the RXRs family members, polymorphisms and T2DM were seldom studied. Therefore, this study was directed to figure out the correlation between single-nucleotide polymorphisms (SNPs) rs2076310 and rs2744537 of $R X R \beta$ gene and genetic sensitivity to T2DM in Chinese Han people from Guangdong province.

\section{SUBJECTS AND METHODS}

\section{Subjects}

According to the criteria of the WHO in 1999, 1092 patients with confirmed T2DM were recruited at 10 hospitals from Shenzhen, Dongguan, Maoming, Zhanjiang and Shaoguan of Guangdong Province from November 2011 to October 2013. In addition, 1092 ethnically matched healthy controls were also subsumed after body checks in the above hospitals. The inclusive criteria of T2DM patients and control were as showed in Table1. The demographic data and clinical data of all subjects were collected by the standardized questionnaire method. About $5 \mathrm{ml}$ peripheral blood samples were collected in the early morning for detecting clinical, biochemical indications as laboratory data. Details of related data showed in Table 2.

Table 1 The inclusive criteria of T2DM patients and control

\begin{tabular}{ll}
\hline Groups & \multicolumn{1}{c}{ Inclusive criteria } \\
\hline T2DM* & (1) Range of ages 20-70; \\
& (2) Random blood glucose levels $\geq 11.1 \mathrm{mmol} / \mathrm{L}$ with diabetes \\
& symptoms including polydipsia, polyphagia, polyuria, weight \\
& loss, itchiness, blurred vision, and other acute metabolic \\
& disorders caused by hyperglycemia; \\
& (3) fasting blood glucose levels $\geq 7.0 \mathrm{mmol} / \mathrm{L}$ without diabetes \\
& symptoms; \\
(4) Blood glucose levels $\geq 11.1 \mathrm{mmol} / \mathrm{L}$ with a glucose \\
tolerance test after two hours oral dose; \\
(5) Without malignancies, cardiovascular diseases, kidney diseases, \\
and other severe interference diseases. \\
(1) Range of ages 20-70; \\
(5) Without family history of diabetes; \\
(3) Healthy after physical examination including medical \\
history, blood glucose, and other biochemical test results.
\end{tabular}

Table 2 Comparison of baseline data between cases and controls $(\bar{x} \pm s / n)$

\begin{tabular}{|c|c|c|c|c|}
\hline Parameters & $\operatorname{T} 2 \mathrm{DM}(n=1067)$ & $\operatorname{Control}(n=1054)$ & $t / x^{2}$ & $P$ \\
\hline \multicolumn{5}{|l|}{ Demographic data } \\
\hline Gender $\left(\mathrm{M} / \mathrm{F}^{*}\right)$ & $532 / 535$ & $532 / 522$ & 0.08 & 0.080 \\
\hline Age (yr) & $59.71 \pm 11.87$ & $57.23 \pm 10.41$ & 5.12 & $<0.001$ \\
\hline $\mathrm{BMI} \dagger\left(\mathrm{kg} / \mathrm{m}^{2}\right)$ & $24.60 \pm 3.24$ & $23.58 \pm 3.33$ & 7.15 & $<0.001$ \\
\hline \multicolumn{5}{|l|}{ Clinical/laboratory data } \\
\hline FPG $(\mathrm{mmol} / \mathrm{L})$ & $10.46 \pm 4.50$ & $5.60 \pm 1.60$ & 33.22 & $<0.001$ \\
\hline Hypertension (Y/N $\ddagger)$ & $396 / 671$ & $380 / 674$ & 0.26 & 0.257 \\
\hline Heartrate (bpm) & $76.40 \pm 15.26$ & $76.20 \pm 10.92$ & 0.35 & 0.682 \\
\hline $\mathrm{TC}(\mathrm{mmol} / \mathrm{L})$ & $5.31 \pm 1.59$ & $5.43 \pm 1.27$ & -1.92 & 0.056 \\
\hline Triglyceride (mmol/L) & $2.24 \pm 1.03$ & $1.31 \pm 0.96$ & 21.51 & $<0.001$ \\
\hline HDL-C (mmol/L) & $1.35 \pm 0.54$ & $1.37 \pm 0.42$ & -0.95 & 0.398 \\
\hline LDL-C (mmol/L) & $2.73 \pm 1.04$ & $3.03 \pm 0.65$ & -7.98 & $<0.001$ \\
\hline
\end{tabular}

${ }^{\star} \mathrm{M} / \mathrm{F}$ is Male to Female; $\uparrow \mathrm{BMI}$ (Body Mass Index) is a person's weight in kilograms divided by the square of height in meters; $\ddagger \mathrm{Y} / \mathrm{N}$ is Yes to No 
This study was conducted correspondingly the Helsinki Declaration of the World Medical Association and ratified by the Ethics Committee. All participants who signed informed consent for this research were the permanent residents of Han nationality in Guangdong province, and there is no blood relationship among them.

\section{DNA preparation}

Peripheral venous blood $(2 \mathrm{~mL})$ was collected from each subject in an anticoagulant tube with ethylenediaminetetraacetic acid disodium salt-Na2 (k2-EDTA). The DNA was extracted by the salting-out method after digestion with Proteinase $\mathrm{K}$ and stored in a $-80^{\circ} \mathrm{C}$ refrigerator.

\section{Screen and genotyping of single-nucleotide polymorphisms}

For the screen of the SNP, the linkage disequilibrium and haplotype block analyses were performed using HapMap phase genotype data (release 27, http://www.hapmap.org) by Haploview 4.2 (Broad Institute, Cambridge, MA). The amplicon was a region with $R X R \beta$ and proximately $5 \mathrm{~kb}$ upstream and downstream respectively of the gene. Ultimately two SNPs (rs2744537 and rs2076310) with minor allele frequency (MAF) $\geq 0.05$ and $r^{2} \geq 0.8$ were chosen. The potential function of SNPs was predicted using FastSNP (http://fastsnp.ibms.sinica.edu.tw). rs2744537 (located in the $5^{\prime}$ upstream) and rs2076310 (located in the intron3) of $R X R \beta$ gene was identified with a high predicted score.

SNPs rs2744537 and rs2076310 were subsequently genotyped by SNPscan ${ }^{\mathrm{TM}}$ technique. Specific experimental steps were as follows: (1) Detection of DNA quality and concentration. Run a DNA sample $(1 \mu \mathrm{l})$ on $1 \%$ agarose gel. (2) Sample lysis. Take $4 \mu \mathrm{L}$ DNA samples into 96-well plates, mix with $2.5 \mu \mathrm{L} 4 \times$ DNA lysis Buffer and $3.5 \mu \mathrm{L}$ distilled water, centrifuge after covering with parafilm, incubate in PCR machine at $98^{\circ} \mathrm{C}$ for $5 \mathrm{~min}$, then store in the ice immediately. (3) Adapter ligation reaction. Add $10 \mu \mathrm{L}$ premix solution to DNA lysis samples, shaking slightly after covering with film, centrifuge for $30 \mathrm{~s}$ at $3000 \mathrm{rpm}$, transfer to PCR machine with four cycles at $94^{\circ} \mathrm{C}$ for $1 \mathrm{~min}$ and $58^{\circ} \mathrm{C}$ for $4 \mathrm{~h}$, then 2 min hold at $4^{\circ} \mathrm{C}$, and at $72^{\circ} \mathrm{C}$ forever. (4) Multiplex polymerase chain reaction. Take $1 \mu \mathrm{L}$ ligation product into a new 96-well plate and mix with $19 \mu \mathrm{L}$ PCR premix solution, centrifuge for $30 \mathrm{~s}$ at $3000 \mathrm{rpm}$ after covering and shaking, transfer to PCR machine to carry out. (5) DNA sequencing. Take $1 \mu \mathrm{L}$ PCR product after diluting 10 times and mix with $0.5 \mu \mathrm{L}$ Liz500 SIZE STANDARD and $8.5 \mu \mathrm{L} \mathrm{Hi-Di,}$ denaturation at $95^{\circ} \mathrm{C}$ for $5 \mathrm{~min}$. The DNA sequencing was performed using an ABI3130XL sequencer. (6) Data analysis. The experimental data were analyzed using GeneMapper 4.1 (Applied Biosystems, USA) to obtain the fluorescent labeling and length of the PCR product, the corresponding gene information of the SNP site and allele.

\section{Statistical analysis}

The $x^{2}$ test was used to calculate the Distributions of the allele and genotype frequencies. Multivariate logistic regression was used to calculate the odds ratios (ORs) and 95\% confidence intervals (95\% CIs) after adjusting covariate. SPSS 20.0 (SPSS Inc., Chicago, USA) was used for data analysis. The Hardy-Weinberg equilibrium test was completed by PLINK (http://pngu.mgh.harvard.edu/ purcell/ plink). Four models (Additive, dominant, recessive, and over-dominant) were used to test the association between gene polymorphisms and T2DM. Measurement data were expressed by the mean \pm standard deviation $(\bar{x} \pm s)$. The two-sided $P<0.05$ was deemed statistically different.

\section{RESULTS}

\section{General situation}

In this case-control study, excluding individuals with SNP missing rate higher than 20\%, 1067 cases and 1054 controls were finally included for statistical analysis. In the case group, there were 535 females and 532 males, average age $59.71 \pm 11.87$ years, while in the control group, there were 522 females and 532 males, average age $57.23 \pm 10.41$ years. There were significant differences in the age composition, BMI (body mass index), FPG (fasting blood glucose), triglyceride levels and LDL-C (low-density cholesterol) between the two groups. The age composition, BMI, FPG, and triglyceride levels of the patient with T2DM were higher than that of the control. Conversely, LDL-C of the patient with T2DM was lower than that of the control, as shown in Table 2.

\section{Comparison between $R X R \beta$ gene polymorphisms genotype and allele frequency}

We not observed statistical differences at the frequencies of all alleles and genotypes (rs2744537 and rs2076310) between the two groups. The Hardy-Weinberg equilibrium $P$ value was more than 0.01 in both SNPs, as shown in Table 3.

\section{Comparison of genetic models}

There were no significant differences in Additive, dominant, recessive, and over-dominant genetic models of $R X R \beta$ polymorphisms (rs2744537 and rs2076310) before and after adjusting the covariant factors including age and body mass index (BMI), as shown in Table 4.

\section{Haplotype analysis}

By linkage disequilibrium analysis, we found that the rs2076310 and rs2744537 of $R X R \beta$ gene have linkage disequilibrium. However, no significant differences were found in the relationship between haplotype variations and T2DM prevalence were evaluated by calculating the ORs and 95\% CIs from multivariate logistic regression with adjustment for gender, age, and BMI, as shown in Table 5.

\section{DISCUSSION}

In our research, we screened two tagging SNPs of the $R X R \beta$ gene to figure out the correlated with the prevalence risk of T2DM in Chinese Han people from Guangdong using a middling sample size of 1067 T2DM patients and 1054 healthy controls. By the single locus analysis, we not found statistical differences between T2DM patients and controls in allele and genotype distribution of two SNPs (rs2744537 and rs2076310) of $R X R \beta$ gene. $R X R \beta$ is a member of the RXR family of nuclear receptors and is confirmed the localization of $R X R \beta$ to chromosome 6p21.3-p21.1. ${ }^{26}$ The receptor is a transcription factor that mediates a range of extracellular signals in a ligand-dependent manner and regulating 
Table 3 Comparison of the allele and genotype frequencies of the two SNPs in RXR $\beta$ in cases and controls $(n)$

\begin{tabular}{|c|c|c|c|c|c|}
\hline SNPs & & $\mathrm{T} 2 \mathrm{DM}(n=1067)$ & $\operatorname{Control}(n=1054)$ & $P$ & OR $(95 \% \mathrm{CI}) \ddagger$ \\
\hline \multicolumn{6}{|l|}{ rs2744537 } \\
\hline \multirow[t]{2}{*}{ Allele } & A & 32 & 35 & \multicolumn{2}{|c|}{ Reference } \\
\hline & $\mathrm{C}$ & 2102 & 2073 & 0.674 & $0.93(0.57-1.52)$ \\
\hline \multirow[t]{4}{*}{ Genotype* } & $\mathrm{CC}$ & 1036 & 1019 & \multicolumn{2}{|c|}{ Reference } \\
\hline & $\mathrm{CA}$ & 30 & 35 & 0.499 & $0.88(0.53-1.45)$ \\
\hline & $\mathrm{AA}$ & 1 & 0 & $-\dagger$ & $-\dagger$ \\
\hline & HWE $\$$ & & & 0.955 & \\
\hline \multicolumn{6}{|l|}{ rs2076310 } \\
\hline \multirow[t]{2}{*}{ Allele } & A & 780 & 771 & \multicolumn{2}{|c|}{ Reference } \\
\hline & G & 1354 & 1337 & 0.987 & $0.96(0.85-1.10)$ \\
\hline \multirow[t]{4}{*}{ Genotype $^{*}$} & GG & 422 & 425 & \multicolumn{2}{|c|}{ Reference } \\
\hline & GA & 510 & 487 & 0.569 & $1.00(0.83 \sim 1.21)$ \\
\hline & $\mathrm{AA}$ & 135 & 142 & 0.754 & $0.91(0.69 \sim 1.20)$ \\
\hline & HWE $\$$ & & & 0.938 & \\
\hline
\end{tabular}

* The $P$ values of rs2744537 and rs2076310 genotype distribution between T2DM patients and controls were $0.499,0.739$, respectively; $\dagger x^{2}$ test cannot be conducted due to cross tabulation of zero; $¥$ ORs and $95 \%$ CIs of genotype frequencies were covariate adjusted; $₫$ HWE is Hardy-Weinberg equilibrium

Table 4 Comparison of the genetic model of RXR $\beta$ ploymorphisms between cases and controls $(n)$

\begin{tabular}{|c|c|c|c|c|c|}
\hline Model & & $\mathrm{T} 2 \mathrm{DM}(n=1067)$ & $\operatorname{Control}(n=1054)$ & $P^{*}$ & $\mathrm{OR}(95 \% \mathrm{CI}) \ddagger$ \\
\hline \multicolumn{6}{|l|}{ rs2744537 } \\
\hline \multirow[t]{2}{*}{ Additive } & $\mathrm{CC}$ & 1036 & 1019 & \multicolumn{2}{|c|}{ Reference } \\
\hline & AA & 1 & 0 & $-\dagger$ & $-\dagger$ \\
\hline \multirow[t]{2}{*}{ Dominant } & $\mathrm{CC}$ & 1036 & 1019 & \multicolumn{2}{|c|}{ Reference } \\
\hline & $\mathrm{CA}+\mathrm{AA}$ & 31 & 35 & 0.582 & $0.90(0.55-1.49)$ \\
\hline \multirow[t]{2}{*}{ Recessive } & $\mathrm{CC}+\mathrm{CA}$ & 1066 & 1054 & \multicolumn{2}{|c|}{ Reference } \\
\hline & $\mathrm{AA}$ & 1 & 0 & $-\dagger$ & $-\dagger$ \\
\hline \multirow[t]{2}{*}{ Overdominant } & $\mathrm{CC}+\mathrm{AA}$ & 1037 & 1019 & \multicolumn{2}{|c|}{ Reference } \\
\hline & $\mathrm{CA}$ & 30 & 35 & 0.496 & $0.88(0.53-1.45)$ \\
\hline \multicolumn{6}{|l|}{ rs2076310 } \\
\hline \multirow[t]{2}{*}{ Additive } & GG & 422 & 425 & \multicolumn{2}{|c|}{ Reference } \\
\hline & AA & 135 & 142 & 0.754 & $0.98(0.86 \sim 1.12)$ \\
\hline \multirow[t]{2}{*}{ Dominant } & GG & 422 & 425 & \multicolumn{2}{|c|}{ Reference } \\
\hline & $\mathrm{GA}+\mathrm{AA}$ & 645 & 629 & 0.716 & $0.98(0.82 \sim 1.17)$ \\
\hline \multirow[t]{2}{*}{ Recessive } & $\mathrm{GG}+\mathrm{GA}$ & 932 & 912 & \multicolumn{2}{|c|}{ Reference } \\
\hline & AA & 135 & 142 & 0.575 & $0.91(0.70 \sim 1.17)$ \\
\hline \multirow[t]{2}{*}{ Overdominant } & $\mathrm{GG}+\mathrm{AA}$ & 557 & 567 & \multicolumn{2}{|c|}{ Reference } \\
\hline & GA & 510 & 487 & 0.462 & $1.03(0.86 \sim 1.22)$ \\
\hline
\end{tabular}

${ }^{\star}$ The $P$ values of rs2744537 and rs2076310 genotype distribution in genetic model between T2DM patients and controls were calculated by $x^{2}$ test; $\dagger x^{2}$ test cannot be conducted due to cross tabulation of zero; $\ddagger$ ORs and $95 \%$ CIs of genotype frequencies were covariate adjusted

Table 5 Haplotype analysis of RXR $\beta$ polymorphisms

\begin{tabular}{ccccc}
\hline \multicolumn{2}{c}{ Haplotype* $^{*}$} & Frequency & OR $\dagger(95 \% \mathrm{CI})$ & $P$ \\
\cline { 1 - 4 } rs2744537 & rs2076310 & & Reference & \\
\cline { 2 - 3 } C & $\mathrm{G}$ & 0.634 & $0.97(0.85-1.10)$ & 0.610 \\
$\mathrm{C}$ & $\mathrm{A}$ & 0.350 & $0.92(0.56-1.50)$ & 0.733 \\
$\mathrm{~A}$ & $\mathrm{~A}$ & 0.016 &
\end{tabular}

* Haplotype of rs2744537 (C/A) and rs2076310 (G/A); † ORs and 95\% CIs of haplotype frequencies were covariate adjusted by logistic regression analysis the target gene by binding to reactive elements within the promoter regions of these genes. ${ }^{27}$ RXRs form heterodimers with another nuclear receptor to vitamin D. Vitamin D plays a significant role in modifying the risk of T2DM in diverse recently published studies, with the effect which is likely mediated by an effect of vitamin D on beta-cell function, insulin sensitivity, and systemic inflammation. ${ }^{28}$ In addition, genetic polymorphisms of vitamin D-related genes may increase T2DM and gestational diabetes mellitus (GDM) risk. ${ }^{29,30}$ Thereinto, it is noteworthy that two SNPs of vitamin D-related genes ( $R X R G$ rs17429130 and RXRA rs4917356) were significantly associated 
with the increased risk of GDM. However, $R X R \beta$ gene polymorphisms were not associated with the increased risk of GDM. The expression pattern of RXR subtypes is quite different. $R X R \alpha$ is abundantly expressed in liver, kidney, spleen, placenta, epidermis and various visceral tissues; $R X R \beta$ is abroad expressed and can be observed in almost every tissue; $R X R \gamma$ expression is primarily restricted to brain and muscle. ${ }^{31}$ Hepatocyte $R X R \alpha$ affects many metabolic processes and has played an important role in lipid homeostasis. Skeletal muscle was the main target of rexinoid (synthetic RXR agonists) as insulin sensitizers action, which sensitizes diabetic skeletal muscle to insulin-dependent glucose treatment. Rexinoids increase uptake and oxidation of saturated fatty acids in cultured skeletal muscle cells from diabetic humans. ${ }^{32}$ To our knowledge, Insulin resistance is often correlated with the accumulation of saturated fatty acids in muscle, which interferes with insulin signaling and glucose uptake. ${ }^{33}$ Interestingly, the study by Codner et al. ${ }^{34}$ found that three RXR subtypes expression in human skeletal muscle is not closely controlled by insulin, insulin resistance or T2DM. Instead, RXR isoform may be a constitutive protein or be controlled by other factors. Therefore, the relationship between RXR gene individual subtype polymorphism and diabetes is worth clarification.

Although they may not be the actual risk mutation, the synonymous SNPs may be highly linked to a variant associated with the translation of the mRNA and protein expression..$^{35}$ For example, the strong association of Wegener's granulomatosis (WG) with the $H L A-D P B 1^{\star} 0401$ allele was confirmed, and an extended haplotype $D P B 1^{\star} 0401 / R X R B^{\star} 03$ was identified showing an even stronger association with WG. ${ }^{36}$ We speculate that this might be due to the RXRB gene is localized in the major histocompatibility complex (MHC) region between HLA-DPB1 and DAXX. Additionally, the significant linkage disequilibrium between the $R X R B$ alleles and some of $H L A-D P B 1$ alleles was revealed by family studies. ${ }^{37}$ However, the data regarding three haplotypes frequency (CG, CA and AA) in T2DM patients compared to controls not observed statistically significant differences, whatever the frequency was covariate-adjusted by logistic regression analysis. This result indicates that this haplotypes, according to the RXRB polymorphisms, might not be genetic factors for predisposition to T2DM in Chinese Han population from Guangdong.

In our study, several limitations should be considered. First of all, both cases and controls were from hospitals, so that the study subjects may not be fully representative of the general population. Furthermore, although $<5 \%$ of each locus of the DNA samples failed for genotyping, this may still be some selection bias. Last but not least, T2DM is a complex, multifactorial disease. Both genetic and environmental factors are known to contribute to its development, a class of uncontrol factors may cause confounding bias. In addition, the limitations of our study also relate to the sample size and the restriction of the population (from Guangdong in China only).

\section{CONCLUSION}

In conclusion, this study suggests that the genetic susceptibility to T2DM may be not associated with SNPs rs2744537 and rs2076310 of $R X R \beta$ gene in the Chinese Han population from Guangdong province. However, it is limited for the research samples only from Han nationality in Guangdong province, so it could not temporarily define that $R X R \beta$ gene polymorphisms are not associated with genetic susceptibility to type 2 diabetes.

\section{REFERENCES}

1. International Diabetes Federation IDF Diabetes Atlas, 8th edition. 2019-05-09. http://www.diabetesatlas.org.

2. Global Report on Diabetes. World Health Organization, 2016.

3. Bruno G, Runzo C, Cavallo-Perin P, Merletti F, Rivetti M, Pinach S, Novelli G, Trovati M, Cerutti F, Pagano G. Incidence of type 1 and type 2 diabetes in adults aged 30-49 years: the population-based registry in the province of Turin, Italy. Diabetes Care 2005; 28(11): 2613-9.

4. Holman N, Young B, Gadsby R. Current prevalence of Type 1 and Type 2 diabetes in adults and children in the UK. Diabet Med 2015; 32(9): 1119-20.

5. Basu S, Yoffe P, Hills N, Lustig RH. The relationship of sugar to population-level diabetes prevalence: an econometric analysis of repeated cross-sectional data. PLoS One 2013; 8(2): e57873.

6. Mangelsdorf DJ, Borgmeyer U, Heyman RA, Zhou JY, Ong ES, Oro AE, Kakizuka A, Evans RM. Characterization of three RXR genes that mediate the action of 9-cis retinoic acid. Genes Dev 1992; 6(3): 329-44.

7. Morishita KI, Kakuta H. Retinoid X Receptor Ligands with Anti-Type 2 Diabetic Activity. Curr Top Med Chem 2017; 17(6): 696-707.

8. Chen G, Zhang Y, Lu D, Li NQ, Ross AC. Retinoids synergize with insulin to induce hepatic Gck expression. Biochem J 2009; 419(3): 645-53.

9. Lehmann JM, Moore LB, Smith-Oliver TA, Wilkison WO, Willson TM, Kliewer SA. An antidiabetic thiazolidinedione is a high-affinity ligand for peroxisome proliferator-activated receptor gamma (PPAR gamma). J Biol Chem 1995; 270(22): 12953-6.

10. Leid M, Kastner P, Chambon P. Multiplicity generates diversity in the retinoic acid signalling pathways. Trends Biochem Sci 1992; 17(10): 427-33.

11. Heyman RA, Mangelsdorf DJ, Dyck JA, Stein RB, Eichele G, Evans RM, Thaller C. 9-cis retinoic acid is a high affinity ligand for the retinoid X receptor. Cell 1992; 68(2): 397-406.

12. Hong SE, Ahn IS, Jung HS, Rayner DV, Do MS. Effect of retinoic acid on leptin, glycerol, and glucose levels in mature rat adipocytes in vitro. J Med Food 2004; 7(3): 320-6.

13. Miyazaki S, Taniguchi H, Moritoh Y, Tashiro F, Yamamoto T, Yamato E, Ikegami H, Ozato K, Miyazaki J. Nuclear hormone retinoid X receptor (RXR) negatively regulates the glucose-stimulated insulin secretion of pancreatic ss-cells. Diabetes 2010; 59(11): 2854-61.

14. Ouadah-Boussouf N, Babin PJ. Pharmacological evaluation of the mechanisms involved in increased adiposity in zebrafish triggered by the environmental contaminant tributyltin. Toxicol Appl Pharmacol 2016; 294: 32-42.

15. Shoucri BM, Martinez ES, Abreo TJ, Hung VT, Moosova Z, Shioda T, Blumberg B. Retinoid X Receptor Activation Alters the Chromatin Landscape To Commit Mesenchymal Stem Cells to the Adipose Lineage. Endocrinology 2017; 158(10): 3109-3125.

16. Inaba T, Matsuda M, Shimamura M, Takei N, Terasaka N, Ando Y, Yasumo H, Koishi R, Makishima M, Shimomura I. Angiopoietin-like protein 3 mediates hypertriglyceridemia induced by the liver $\mathrm{X}$ receptor. J Biol Chem 2003; 278(24): 21344-51.

17. Canan Koch SS, Dardashti LJ, Hebert JJ, White SK, Croston GE, Flatten KS, Heyman RA, Nadzan AM. Identification of the first retinoid X, receptor homodimer antagonist. J Med Chem 1996; 39(17): 3229-34.

18. Gernert DL, Neel DA, Boehm MF, Leibowitz MD, Mais DA, Michellys 
PY, Rungta D, Reifel-Miller A, Grese TA. Design and synthesis of benzofused heterocyclic RXR modulators. Bioorg Med Chem Lett 2004; 14(11): 2759-63.

19. Zhang H, Zhou R, Li L, Chen J, Chen L, Li C, Ding H, Yu L, Hu L, Jiang $\mathrm{H}$, Shen $\mathrm{X}$. Danthron functions as a retinoic $\mathrm{X}$ receptor antagonist by stabilizing tetramers of the receptor. J Biol Chem 2011; 286(3): 1868-75.

20. Yotsumoto T, Naitoh T, Kanaki T, Tsuruzoe N. A retinoid X receptor antagonist, HX531, improves leptin resistance without increasing plasma leptin level in KK-Ay mice under normal dietary conditions. Metabolism 2005; 54(5): 573-8.

21. Yamauchi T, Waki H, Kamon J, Murakami K, Motojima K, Komeda K, Miki H, Kubota N, Terauchi Y, Tsuchida A, Tsuboyama-Kasaoka N, Yamauchi N, Ide T, Hori W, Kato S, Fukayama M, Akanuma Y, Ezaki O, Itai A, Nagai R, Kimura S, Tobe K, Kagechika H, Shudo K, Kadowaki T. Inhibition of RXR and PPARgamma ameliorates diet-induced obesity and type 2 diabetes. J Clin Invest 2001; 108(7): 1001-13.

22. Nakatsuka A, Wada J, Hida K, Hida A, Eguchi J, Teshigawara S, Murakami K, Kanzaki M, Inoue K, Terami T, Katayama A, Ogawa D, Kagechika H, Makino H. RXR antagonism induces G0 /G1 cell cycle arrest and ameliorates obesity by up-regulating the p53-p21(Cip1) pathway in adipocytes. J Pathol 2012; 226(5): 784-95.

23. Wang G, Xu X, Yao X, Zhu Z, Yu L, Chen L, Chen J, Shen X. Latanoprost effectively ameliorates glucose and lipid disorders in $\mathrm{db} / \mathrm{db}$ and ob/ob mice. Diabetologia 2013; 56(12): 2702-12.

24. Lu Y, Ye X, Cao Y, Li Q, Yu X, Cheng J, Gao Y, Ma J, Du W, Zhou L. Genetic variants in peroxisome proliferator-activated receptorgamma and retinoid $\mathrm{X}$ receptor-alpha gene and type 2 diabetes risk: a case-control study of a Chinese Han population. Diabetes Technol Ther 2011; 13(2): 157-64.

25. Hasstedt SJ, Chu WS, Das SK, Wang H, Elbein SC. Type 2 diabetes susceptibility genes on chromosome 1q21-24. Ann Hum Genet 2008; 72(Pt 2): 163-9.

26. Fitzgibbon J, Gillett GT, Woodward KJ, Boyle JM, Wolfe J, Povey S. Mapping of RXRB to human chromosome 6p21.3. Ann Hum Genet 1993; 57(Pt 3): 203-9.
27. Dawson MI, Xia Z. The retinoid X receptors and their ligands. Biochim Biophys Acta 2012; 1821(1): 21-56.

28. Grammatiki M, Rapti E, Karras S, Ajjan RA, Kotsa K. Vitamin D and diabetes mellitus: Causal or casual association? Rev Endocr Metab Disord 2017; 18(2): 227-241.

29. Safar HA, Chehadeh SEH, Abdel-Wareth L, Haq A, Jelinek HF, Elghazali G, Anouti FA. Vitamin D receptor gene polymorphisms among Emirati patients with type 2 diabetes mellitus. J Steroid Biochem Mol Biol 2018; 175: 119-124.

30. Shi A, Wen J, Liu G, Liu H, Fu Z, Zhou J, Zhu Y, Liu Y, Guo X, Xu J. Genetic variants in vitamin $\mathrm{D}$ signaling pathways and risk of gestational diabetes mellitus. Oncotarget 2016; 7(42): 67788-67795.

31. Nohara A, Kobayashi J, Mabuchi H. Retinoid X receptor heterodimer variants and cardiovascular risk factors. J Atheroscler Thromb 2009; 16(4): 303-18.

32. Szanto A, Narkar V, Shen Q, Uray IP, Davies PJ, Nagy L. Retinoid X receptors: X-ploring their (patho)physiological functions. Cell Death Differ 2004; 11 Suppl 2: S126-43.

33. Petersen KF, Shulman GI. Pathogenesis of skeletal muscle insulin resistance in type 2 diabetes mellitus. Am J Cardiol 2002; 90(5A): 11G-18G.

34. Codner E, Loviscach M, Ciaraldi TP, Rehman N, Carter L, Mudaliar S, Henry RR. Retinoid X receptor expression in skeletal muscle of nondiabetic, obese and type 2 diabetic individuals. Metabolism 2001; 50(7): 830-4.

35. Sauna ZE, Kimchi-Sarfaty C. Understanding the contribution of synonymous mutations to human disease. Nat Rev Genet 2011; 12(10): 683-91.

36. Jagiello P, Gencik M, Arning L, Wieczorek S, Kunstmann E, Csernok E, Gross WL, Epplen JT. New genomic region for Wegener's granulomatosis as revealed by an extended association screen with 202 apoptosis-related genes. Hum Genet 2004; 114(5): 468-77.

37. Rajsbaum R, Fici D, Fraser PA, Flores-Villanueva PO, Awdeh ZL. Polymorphism of the human retinoid $\mathrm{X}$ receptor beta and linkage disequilibrium with HLA-DPB1. Tissue Antigens 2001; 58(1): 24-9. 